\title{
ELABORAÇÃO DE PROJETOS DE PESQUISA - PUBLICAÇÃO - FINANCIAMENTO E OU FOMENTO (ARTIGO DE INFORMAÇÃO)
}

\author{
Autor: Professor Doutor Carlos Jorge Rocha Oliveira \\ Biólogo CRBio 19428/01D
}

Proponho nesta comunicação fazer uma breve definição de projeto de pesquisa científica as formas mais convencionais de publicação e de solicitação de financiamento para os projetos, busca de fomento.

\section{Pesquisa}

Projeto de pesquisa define os caminhos para abordar uma certa realidade. Oferece respostas como: 1. O que pesquisar? Por que pesquisar? (Justificativa); 2. Para que pesquisar? (Objetivos); 3. Como pesquisar? (Metodologia); 4. Quando pesquisar? (Cronograma); 5. Por quem? (Pesquisadores).

Somente o planejamento não sugere ou confere sucesso ao trabalho proposto, mas sem dúvida é um bom caminho a ser seguido.

Outro item importante é a racionalidade na elaboração do projeto de pesquisa, onde a vinculação estrutural do campo teórico com a realidade pesquisada deve atender a um critério de coerência para sua publicação e ainda busquem os objetivos com razoabilidade técnica com um menor custo de investimento.

\section{Publicação}

\section{Projetos para artigos originais}

São contribuições destinadas a divulgar resultados de pesquisas originais que possam ser generalizados ou replicados. Incluem estudos controlados e randomizados, estudos de testes diagnósticos e de triagem e de outros estudos descritivos e de intervenção, bem como a pesquisa básica com animais de laboratório.

\section{Projetos para relatos de casos ou caso clínico}

São trabalhos de observações clínicas originais acompanhados de análise e discussão. Tratam de pacientes ou situações singulares, doenças raras ou nunca descritas, assim como formas inovadoras de diagnóstico ou tratamento. O texto é composto por uma introdução breve que situa o leitor quanto à importância do assunto e apresenta o objetivo da apresentação do caso; por um relato resumido do caso; e por comentários que discutem aspectos relevantes e comparam o relato com outros casos descritos na literatura.

\section{Projetos para artigos de revisão}

É a avaliação crítica sistemática da literatura sobre determinado assunto, devendo conter conclusões. A organização do texto do artigo, com exceção da Introdução, Discussão e Conclusão, fica a critério do autor.

\section{Projetos para artigos especiais}

São textos não classificáveis nas categorias acima, que o Conselho Editorial da revista julgue de especial relevância para as ciências da saúde ou ensino na área da saúde. Sua revisão admite critérios próprios, não havendo limite de tamanho ou exigência prévias quanto as referências bibliográficas.

Todo e qualquer projeto tem um custo financeiro que deve constar no seu orçamento quanto da submissão ao seu setor de pesquisa. Uma das formas mais usuais de viabilizar um projeto de pesquisa é buscar seu financiamento e ou fomento em órgãos municipais, estaduais e federais, os quais devem estar ligadas ao seu grupo de pesquisa ou sua instituição de ensino/pesquisa.

\section{Financiamento / Fomento}


FAPESP - Fundação de Amparo à Pesquisa do Estado de São Paulo.

CNPQ - Conselho Nacional de Desenvolvimento Científico e Tecnológico.

FINEP - Financiadora de Estudos e Projetos.

FAPESP - Fundação de Amparo à Pesquisa do Estado de São Paulo (www.fapesp.br).

Auxílio à Pesquisa - Regular - oferece financiamento para projetos de pesquisa individuais a serem desenvolvidos sob a responsabilidade de um Pesquisador Responsável com título de doutor ou qualificação equivalente avaliada por sua súmula curricular, vinculado a entidades de ensino superior e pesquisa, públicas ou privadas, no Estado de São Paulo.

Auxílio à Pesquisa - Projeto Temático - destina-se a apoiar propostas de pesquisa com objetivos suficientemente ousados, que justifiquem a duração de até cinco anos e as condições especialmente favorecidas de apoio e financiamento, incluindo a possibilidade de concessão de solicitações complementares vinculadas a projeto.

Auxílio à Pesquisa - Pesquisador Visitante destina-se a cobrir, total ou parcialmente, as despesas referentes à visita de pesquisador experiente, vinculado a instituição de pesquisa do exterior ou do Brasil a uma instituição de pesquisa no Estado de São Paulo, por um período contínuo e não superior a um ano.

Auxílio à Pesquisa - Organização de Reunião Científica e/ou Tecnológica - Destina-se a apoiar parcialmente a realização de reunião que seja de reconhecida importância para o intercâmbio científico ou tecnológico para participação de pesquisadores do Estado de São Paulo. A solicitação pode ser feita em qualquer época do ano.

Auxílio à Pesquisa - Participação em Reunião Científica e/ou Tecnológica - Destina-se a financiar parcialmente a participação de pesquisadores do Estado de São Paulo em reuniões científicas ou tecnológicas, no Brasil ou no exterior, para apresentação de trabalho de sua autoria, não publicado, resultado de projeto de pesquisa financiado pela FAPESP, que exponha resultados inéditos de pesquisa.

Auxílio à Pesquisa - Publicações - oferece fi- nanciamento para a publicação de periódicos, artigos e livros que exponham resultados originais de pesquisa realizada por pesquisador com título de doutor ou qualificação equivalente, vinculado a instituição de ensino superior e pesquisa, pública ou privada, no Estado de São Paulo. O pesquisador solicitante deve ser autor, co-autor ou orientador do trabalho objeto da solicitação de auxílio.

\section{Conselho Nacional de Desenvolvimento Científico Tecnológico - CNPQ (www.cnpq.br)}

Auxílio Pesquisador Visitante - APV - Norma

\section{Específica}

Possibilitar ao pesquisador brasileiro ou estrangeiro, de reconhecida competência, a colaboração com grupos de pesquisa, de instituições públicas ou comunitárias nacionais, para o desenvolvimento de linhas de pesquisa ou desenvolvimento tecnológico.

Ver Calendário: http://www.cnpq.br/calendario/index.htm

Auxílio Participação em Eventos Científicos AVG - Norma Específica

Apoiar a participação de pesquisador com desempenho destacado em sua área de atuação em eventos científicos no exterior, tais como: congressos e similares, intercâmbio científico ou tecnológico; ou visitas de curta duração, para aquisição de conhecimentos específicos e necessários ao desenvolvimento da pesquisa científica ou tecnológica.

Ver Calendário: http://www.cnpq.br/calendario/index.htm

Auxílio Promoção de Eventos Científicos - ARC - Norma Específica

Apoiar a realização no País, de congressos, simpósios, seminários, ciclos de conferências e outros eventos similares de curta duração relacionados à ciência, tecnologia e inovação.

Ver Calendário: http://www.cnpq.br/calendario/index.htm

\section{Auxílio Editoração - AED - Norma Específica}

Apoiar e incentivar a editoração e publicação de periódicos científicos brasileiros impressos, sendo considerado prioritário o apoio às revistas 
divulgadas simultaneamente por meio eletrônico, em todas as áreas do conhecimento. Essas publicações devem ser mantidas e editadas por instituição ou sociedade científica brasileira, sem fins lucrativos, de âmbito nacional e que contribuam para elevar o nível de qualidade, forma e conteúdo das revistas nacionais dedicadas à Ciência, Tecnologia e Inovação, para divulgação no Brasil e no exterior.

Ver Calendário: http://www.cnpq.br/calendario/index.htm

\section{FINEP - Financiadora de Estudos e Projetos (www.finep.gov.br)}

\section{Chamadas Públicas}

Veja as chamadas vigentes, seus formulários e resultados recentes clicando abaixo na lista dos Fundos Setoriais ou outras fontes que estão oferecendo oportunidades de financiamento. (http://www.finep.gov.br/como_obter financiamento/editais_financiamento_ini.asp)

Como Apresentar Propostas

Para obtenção de crédito é necessário preliminarmente apresentar uma Consulta Prévia (CP). (http://www.finep.gov.br/como_ obter_financiamento/formularios_e_manuais. asp\#fap), a qualquer tempo, via formulário. A resposta da FINEP à CP, ou o contato para solicitar esclarecimentos ou informações adicionais, é realizado em prazo não superior a 30 dias corridos.

$\mathrm{Na}$ CP são avaliados o enquadramento da proposta nas modalidades de financiamento da FINEP, a posição da organização no ambiente onde atua, a estratégia de inovação e a capacidade da organização para empreender as ações de PD\&I propostas.

Após o enquadramento da $\mathrm{CP}$, a organização deve preencher o formulário eletrônico da Solicitação de Financiamento (SF). Este deverá ser submetido à FINEP por via eletrônica. Os formulários indicam o detalhamento necessário para os objetivos, os resultados esperados, os indicadores, as metas, a metodologia, a equipe do projeto de inovação e informações econômico-financeiras da organização, que permitirão à FINEP avaliar os impactos da execução da proposta de inovação apresentada para o fortalecimento da estratégia da organização, bem como sua contribuição para o desenvolvimento econômico e social do País.Espero que essa publicação ajude de alguma forma você a ter um melhor entendimento sobre Pesquisa / Publicação / Financiamento ou Fomento.

\section{Bibliografia}

ASSOCIAÇÃO BRASILEIRA DE NORMAS TÉCNICAS. Normas de documentação. Rio de Janeiro: ABNT.

ECO, U. Como se faz uma tese. São Paulo: Perspectiva, $1989.180 \mathrm{p}$.

FACULDADE DE MEDICINA DE CAMPOS. Manual de elaboração e apresentação de trabalhos monográficos. Campos dos Goytacazes, 2002. 53

LAKATOS, E. M., MARCONI, M. A. Metodologia do trabalho científico. 4.ed. São Paulo: Atlas, 2002. $214 \mathrm{p}$.

MARCONI, M. de A., LAKATOS, E. M. Técnicas de pesquisa. 4.ed. São Paulo: Atlas, 2001. 231 p.

MEDEIROS, A. Redação científica. São Paulo: Atlas, 2002.

RUIZ, J. A. Metodologia científica: guia para eficiência nos estudos. São Paulo: Atlas, 1982. 170 p. SEVERINO, A. J. Metodologia do trabalho científico. 22. ed. São Paulo: Cortez, 2002. 252 p. SOUZA, E. S. e, GUSMÃO, H. R. Como normalizar trabalhos científicos: instrução programada. 2. ed. Niterói: EDUFF, 1996. 152 p. 